УДК 334.72

DOI 10.18101/2304-4446-2020-2-15-23

\title{
ОБ ОСОБЕННОСТЯХ РАЗВИТИЯ ПРЕДПРИНИМАТЕЛЬСКИХ СПОСОБНОСТЕЙ У СТУДЕНТОВ
}

\section{(C) Потаев Виктор Сергеевич}

доктор экономических наук, профессор, Бурятский государственный университет имени Доржи Банзарова Россия, 670000, г. Улан-Удэ, ул. Смолина, 24а

E-mail: potaev_viktor@mail.ru

В статье показаны значение предпринимательства как одного из главных экономических факторов производства, особенности людей, занимающихся предпринимательской деятельностью, сделан обзор способов развития предпринимательских способностей. При сравнении черт характера предпринимателей и менеджеров у них было обнаружено много общего. Из отличий можно выделить то, что менеджеры не являются собственниками предприятий, они не новаторы и у них слабее развиты предпринимательские способности. Для определения развития предпринимательских способностей у студентов Института экономики и управления Бурятского государственного университета было проведено их тестирование, вначале на втором курсе, затем на четвертом курсе обучения. Результаты показали, что половина респондентов желает стать предпринимателями. Однако процесс формирования предпринимательских способностей, так называемых мягких навыков, происходит неудовлетворительно. Для развития предпринимательских способностей у студентов рекомендуется внедрить одноименную дисциплину, создать экосреду для формирования стартапов, больше внимания уделять самоподготовке будущих предпринимателей.

Ключевые слова: предпринимательство; предпринимательские способности; компетенции; подготовка; самоподготовка.

\section{Для цитирования}

Потаев В. С. Об особенностях развития предпринимательских способностей у студентов // Вестник Бурятского государственного университета. Экономика и менеджмент. 2020. № 2. C. 15-23.

Как известно, основными экономическими факторами, ресурсами производства являются земля, труд, капитал и предпринимательство. Предпринимательство, или предпринимательские ресурсы, представляют люди, обладающие предпринимательскими способностями, занимающиеся и желающие заниматься предпринимательской деятельностью. Земельные, трудовые и материальнотехнические (капитал) ресурсы без участия предпринимательства сами по себе не могут дать экономического эффекта. Только предпринимательство, соединяя экономические факторы (земля, труд, капитал), создает продукт или услугу. При этом предприниматель (согласно теории «созидательного разрушения» Й. Шумпетера) разрушает прежние неэффективные и создает новые эффективные производства [1].

Для стран с переходной экономикой, какой является и Россия, первоочередное внимание необходимо уделять развитию предпринимательства, в частности подготовке предпринимателей, как в школах, так и в вузах. В деле подготовки 
предпринимательских ресурсов очевидным является учет их особенностей, с точки зрения как человеческих ресурсов, так и особенностей их деятельности.

Изучением значения предпринимательства, людей, реализующих предпринимательскую деятельность, занимались многие ученые [1]. Так, еще в конце XVII - начале XVIII в. французский экономист шотландского происхождения Ричард Кантильон (1725) характеризовал предпринимателя как человека, склонного к риску.

В конце XVIII - начале XIX в. французский экономист Жан Батист Сэй (1803) указывал, что предприниматель - это лицо, которое берется за свой счет и риск и в свою пользу произвести какой-либо продукт.

На рубеже XIX-XX вв. Андре Маршал (1907-1968), рассматривая предпринимательство как 4-й экономический фактор производства, показал предпринимателя как человека, который способен организовать эффективное использование земли, труда и капитала.

Известный американский экономист Йозеф Шумпетер (1883-1950) в книге «Теория экономического развития» трактует понятие «предпринимательство» как новшество, как разработку новых технологий и, следовательно, предпринимателя как человека, занимающегося главным образом организацией и совершенствованием производства.

Примерно так же показывают предпринимателя современные ученыеэкономисты - лауреат Нобелевской премии по экономике 1974 г. Фридрих Альфред фон Хайек (1899-1984), известный американский ученый П. Друкер (1909-2005) и др.

Таким образом, классическая экономика не может представить развитие предприятий, региональной и национальной экономик, развитие инноваций и многого другого без предпринимательства и предпринимателей.

В России понятие о предпринимательстве как о факторе производства, людях, обладающих предпринимательскими способностями, вернулось лишь с началом осуществления экономических реформ, т. е. с конца 80-х - начала 90-х гг. XX в. В советское время оно как ресурс не рассматривалось. Более того, в период командной экономики предпринимателя воспринимали как эксплуататора, мошенника, спекулянта и жулика.

Сейчас ситуация, конечно, в корне изменилась. В соответствии со статьей 2 Гражданского кодекса Российской Федерации (1995) «предпринимательская деятельность - самостоятельная осуществляемая на свой риск деятельность, направленная на систематическое получение прибыли от пользования имуществом, продажи товаров, выполнения работ или оказания услуг лицами, зарегистрированными в этом качестве в установленном в законе порядке». Исходя из данной статьи кодекса, видно, что она не противоречит взглядам ученыхклассиков, и очевидно, чем должен заниматься предприниматель и что он должен уметь делать.

При более глубоком анализе особенностей предпринимателя обнаруживается, что ряд функций, таких как принятие решений, несение ответственности и многое другое, связывает предпринимателя и менеджера и они во многом похожи друг на друга. По факту многие менеджеры в России, в особенности топменеджеры, даже находящиеся на государственной или муниципальной службе, 
параллельно занимаются бизнесом. Разумеется, в таких случаях их бизнес оформлен на супругу, детей или других родственников. Несмотря на все это, нельзя полностью отождествлять предпринимательство и менеджмент. Надо помнить, что предприниматель - это собственник предприятия, работодатель, а менеджер - наемный работник. При этом предприниматели - это не просто хозяева и руководители своих предприятий, они еще и новаторы. В отличие от них, менеджеры выполняют «волю хозяина», «волю предпринимателя(-лей)», будь это государство или предприятие, и нововведения не являются их задачей.

Общие характерные черты предпринимателей и менеджеров, уровень их проявления по авторскому обобщению отображены в таблице 1.

Таблица 1

Общие характерные черты предпринимателей и менеджеров

\begin{tabular}{|l|l|c|c|}
\hline & \multicolumn{1}{|c|}{} & Предприниматели & Менеджеры \\
\hline 1 & Руководители предприятия & + & + \\
\hline 2 & Собственники предприятия & + & - \\
\hline 3 & Новаторы & + & +- \\
\hline 4 & Психологический портрет: & + & +- \\
\hline & а) люди с опорой на собственные силы & + \\
\hline $\begin{array}{l}\text { б) обладающие стремлением к независимости } \\
\text { и жаждой успеха }\end{array}$ & + & +- \\
\hline & в) готовые к риску & + & +- \\
\hline & г) лидеры и обладающие интуицией & + & + \\
\hline & $\begin{array}{l}\text { д) способные постоянно переучиваться и со- } \\
\text { вершенствоваться }\end{array}$ & + \\
\hline
\end{tabular}

Как видно из приведенной таблицы, менеджеры, в отличие от предпринимателей, как было отмечено, не хозяева и не новаторы и у них нечетко выражены психологические черты предпринимателя. У предпринимателя наличие предпринимательских черт характера является разумеющимся, обязательным.

В настоящее время никто не будет оспаривать то, что во многом черты характера предпринимателя передаются по наследству и формируются не столько учебой, а сколько воспитанием. Биография каждого отдельного предпринимателя, естественно, достаточно индивидуальна. Однако анализ жизненного пути предпринимателей показывает, что он во многом похож и свойствен только предпринимателям.

Первое, доказано [4], что предприниматели часто в семье являлись старшими детьми. Действительно, старший или единственный ребенок в семье получает больше родительского внимания, чем другие дети. Это сказывается на формировании психологии ребенка, и он вырастает более самостоятельным и смелым. Другое, по нашей догадке, это то, что старшие дети, приглядывая за младшими братьями и (или) сестрами по указанию родителей, рано приобретают управленческие, менеджерские черты характера.

Второе, это то, что родители предпринимателей чаще всего уже сами предприниматели. Привычка быть свободным, самостоятельно принимать решения и 
многое другое, свойственное предпринимателю, передается детям. Как говорится, «как ни пытайтесь воспитывать детей, все равно они будут похожими на вас».

И, наконец, третье очень важное в семье - это отношения родителей к детям. Предприниматели вырастают в семьях, где всегда поддерживают своего сына или дочь, где поощрялись самостоятельность, трудолюбие и ответственность.

Переходя к школе, школьному образованию, следует отметить, что в системе Министерства просвещения Российской Федерации, куда относится реализация государственной политики по воспитанию, обеспечению среднего общеобразовательного и среднего профессионального образования, в последние годы принимаются меры по формированию экономических знаний и предпринимательских способностей у детей. Например, в общеобразовательных школах экономика стала изучаться в предмете «Обществознание», в виде факультатива изучается статистика по предмету «Математика», как элективный курс - «Основы финансовой грамотности» и т. д. В системе среднего профессионального образования обязательным объявили наличие дисциплин и курсов по предпринимательству.

В высшей школе, в системе Министерства науки и высшего образования Российской Федерации к направлениям подготовки, где много уделяется внимания развитию предпринимательских компетенций, относятся «Экономика», «Менеджмент», «Управление персоналом». Дисциплинами, помогающими студентам сформировать свои знания, навыки и способности в предпринимательстве, можно назвать следующие: «Экономика предприятия», «Бизнес-планирование», «Маркетинг», «Бухгалтерский учет», «Финансы», «Менеджмент», «Управление персоналом» и др.

Например, в ФГБОУ ВО «Бурятский государственный университет имени Доржи Банзарова» тоже практически по всем экономическим направлениям обучения есть дисциплины, связанные с предпринимательством. Однако изучением наличия и формирования предпринимательских способностей у студентовэкономистов никто ранее не занимался.

Для оценки предпринимательских способностей у студентов Института экономики и управления нами было проведено их анкетирование. Вопросы для анкетирования были заимствованы у Р. Хизрича и М. Питерса [2]. Средний возраст студентов был 19 лет, и они учились на 2-м курсе очного обучения. В тесте «Оценка своих предпринимательских способностей» было всего 20 вопросов. Другими тестами были «Опора на внешние и внутренние силы», «Склонность к риску» и «Стремление к независимости». В первом тесте большое внимание было уделено вопросу «Уверены ли Вы в том, что иметь собственное дело - это главная ваша мечта?».

Как видно из таблицы 2, всего было протестировано 74 человека. Из 20 максимальных баллов в среднем студенты набрали 12,6 балла. Наиболее высокие баллы набрали студенты направлений обучения «Бизнес-информатика» $(14,5)$ и «Менеджмент» $(13,0)$, а наименьшее количество баллов - по профилю «Финансы и кредит» $(11,0)$. Самый высокий удельный вес желающих и мечтающих стать предпринимателями отмечено у студентов направления «Бизнес-информатика» $(100 \%)$ и «Менеджмент» $(77,3 \%)$, а самый низкий — «Математические методы в экономике» $(16,7 \%)$ и «Финансы и кредит» $(22,2 \%)$. Самые высокие баллы по наличию предпринимательских способностей (по 16 и более баллов), как прави- 
ло, набирали дети предпринимателей, менеджеров и (или) уже имеющие какието личные успехи (Зоригтуев 3., Мартынко В., Филь А., Каданцева Е., Гомбоева С., Зодбоев В., Доржиева Е., Лощинская А., Тубчинова О.). Кстати, студент Гомбоева С. является мастером спорта по стрельбе из лука, Зодбоев В. - кандидат в мастера спорта по вольной борьбе. Данные анкетирования, на взгляд автора, были довольно обнадеживающими и вызывали оптимизм. В условиях экономического кризиса, при сокращении предприятий и соответственно рабочих мест, оптимизации государственных и муниципальных учреждений ориентация будущих выпускников вуза на создание собственного дела вызывала уважение и восхищение.

Таблица 2

Результаты тестирования студентов «Оценка предпринимательских способностей» (в 2015 г.)

\begin{tabular}{|c|c|c|c|c|c|c|}
\hline \multirow[t]{2}{*}{$\begin{array}{c}\text { Направление / } \\
\text { профиль обучения }\end{array}$} & \multirow[t]{2}{*}{$\begin{array}{c}\text { Всего } \\
\text { протестировано, } \\
\text { чел. }\end{array}$} & \multirow[t]{2}{*}{$\begin{array}{c}\text { В сред- } \\
\text { нем по- } \\
\text { лучено } \\
\text { баллов }\end{array}$} & \multicolumn{2}{|c|}{$\begin{array}{c}\text { Число по- } \\
\text { лучивших } \\
15 \text { и более } \\
\text { баллов }\end{array}$} & \multicolumn{2}{|c|}{$\begin{array}{c}\text { Желающих стать } \\
\text { предпринимателям }\end{array}$} \\
\hline & & & чел. & $\%$ & чел. & $\%$ \\
\hline $\begin{array}{l}\text { Управление персо- } \\
\text { налом }\end{array}$ & 17 & 12,7 & 5 & 29,4 & 8 & 47,1 \\
\hline $\begin{array}{l}\text { Экономика / Финан- } \\
\text { сы и кредит }\end{array}$ & 9 & 11,0 & 0 & 0 & 2 & 22,2 \\
\hline $\begin{array}{l}\text { Экономика / Бухгал- } \\
\text { терский учет и аудит }\end{array}$ & 10 & 12,4 & 2 & 20,0 & 4 & 40,0 \\
\hline $\begin{array}{l}\text { Экономика / Мате- } \\
\text { матические методы } \\
\text { в экономике }\end{array}$ & 6 & 12,8 & 2 & 33,3 & 1 & 16,7 \\
\hline $\begin{array}{l}\text { Бизнес- } \\
\text { информатика }\end{array}$ & 4 & 14,5 & 2 & 50,0 & 4 & 100 \\
\hline $\begin{array}{l}\text { Государственное и } \\
\text { муниципальное } \\
\text { управление }\end{array}$ & 6 & 12,0 & 2 & 33,3 & 3 & 50,0 \\
\hline Менеджмент & 22 & 13,0 & 7 & 31,8 & 17 & 77,3 \\
\hline Итого & 74 & 12,6 & 20 & 27,0 & 39 & 52,7 \\
\hline
\end{tabular}

В 2019 г. эти же студенты, уже на 4-м курсе обучения, в возрасте в среднем 21 года (к сожалению, не все), были вновь протестированы (табл. 3).

Сравнение данных таблиц 2 и 3 показывает, что ситуация по наличию и формированию предпринимательских способностей изменилась незначительно. Так, если на 2-м курсе обучения студентами в среднем по наличию предпринимательских способностей было получено 12,6 баллов, то на 4-м курсе - 13,2. Разница в формировании предпринимательских компетенций у студентов в разрезе направлений и профилей обучения имеется. У студентов, обучающихся по профилю 
«Финансы и кредит», уровень вырос на 9,1\%, «Бухгалтерский учет и аудит»на 10,5\%, «Менеджмент» — на 2,3\%, а по направлению «Бизнес-информатика» произошло даже снижение - $-5,8 \%$.

Таблица 3

Результаты тестирования студентов «Оценка предпринимательских способностей» (в 2019 г.)

\begin{tabular}{|l|c|c|c|c|c|c|}
\hline \multicolumn{1}{|c|}{$\begin{array}{l}\text { Направление / } \\
\text { профиль обучения }\end{array}$} & $\begin{array}{c}\text { Всего } \\
\text { протестировано, } \\
\text { чел. }\end{array}$ & $\begin{array}{c}\text { В сред- } \\
\text { нем по- } \\
\text { лучено } \\
\text { баллов }\end{array}$ & $\begin{array}{c}\text { Число по- } \\
\text { лучивших } \\
\text { балолее } \\
\text { баллов }\end{array}$ & \multicolumn{2}{|c|}{$\begin{array}{c}\text { Желающих стать } \\
\text { предпинимателями }\end{array}$} \\
\cline { 4 - 7 } & 8 & 12,0 & 1 & 12,5 & 1 & 12,5 \\
\hline $\begin{array}{l}\text { Экономика / Финан- } \\
\text { сы и кредит }\end{array}$ & 15 & 13,7 & 6 & 40,0 & 6 & 40,0 \\
\hline $\begin{array}{l}\text { Экономика / Бухгал- } \\
\text { терский учет и аудит }\end{array}$ & 7 & 13,7 & 2 & 28,6 & 5 & 71,4 \\
\hline $\begin{array}{l}\text { Бизнес- } \\
\text { информатика }\end{array}$ & 6 & 13,3 & 2 & 33,3 & 3 & 50,0 \\
\hline Менеджмент & 36 & 13,2 & 12 & 33,3 & 15 & 41,7 \\
\hline Итого & & & & & \\
\hline
\end{tabular}

Анализ ответов респондентов показал, что рост предпринимательских способностей у студентов произошел главным образом благодаря освоению дисциплин «Бухгалтерский учет», «Финансы» и «Маркетинг». По повышению мягких компетенций, таких как умение доводить начатое дело до конца; умение настоять на принятом решении; не бояться ответственности и любить руководить; умение работать, не получая немедленной отдачи; любить общаться и работать с людьми и другим soft skills, никаких изменений не произошло. Хуже того, удельный вес студентов, желающих стать предпринимателями, сократился с 52,7 до 47,7\%. Это свидетельствует о низкой самооценке студентов как будущих предпринимателей. Обычно знания и навыки дают уверенность человеку в том, что он сможет заниматься таким видом деятельности. В нашем случае произошло наоборот, желающих стать предпринимателями стало меньше.

Для изменения ситуации в формировании и развитии предпринимательских способностей нами разработан курс «Развитие предпринимательских способностей». Данный курс одобрен учебно-методическим советом Бурятского государственного университета и рекомендован пока для студентов 2-го курса по направлению «Экономика». Темы предполагаемых лекций, практических и самостоятельных занятий сформированы по вопросам анкеты «Оценка предпринимательских способностей», по Р. Хизричу и М. Питерсу. На наш взгляд, этого крайне недостаточно, в университете необходимо создавать целую экосреду по развитию предпринимательских компетенций у студентов начиная с первого курса. 
B. С. Потаев. Об особенностях развития предпринимательских способностей у студентов

Студент во время своего обучения должен проходить следующие этапы своего развития:

1-й этап (первый курс обучения) - неосознанная некомпетентность. Студент не до конца осознает, куда поступил, что представляет собой его направление, профиль обучения и будущая профессия. Он, соответственно, не знает, какими компетенциями (ОК, ОПК и ПК) он должен овладеть согласно выбранному направлению и профилю обучения. О наличии специальных предпринимательских компетенций студент не имеет понятия.

2-й этап (второй курс обучения) - осознанная некомпетентность по выбранному направлению обучения и профилю и неосознанная некомпетентность по предпринимательству. Студент пока не представляет, какими навыками и умениями он должен обладать как предприниматель.

3-й этап (третий курс обучения) - осознанная некомпетентность по наличию и развитию предпринимательских способностей. Студент осознанно занимается развитием своих предпринимательских компетенций.

4-й этап (четвертый курс обучения) — осознанная компетентность по наличию, развитию и необходимости постоянного повышения предпринимательских способностей.

В идеале за время своего четырехлетнего обучения в вузе, в частности в Бурятском государственном университете, студент - будущий предприниматель должен пройти все эти этапы своего развития. Затем, уже занимаясь предпринимательской деятельностью, он должен перейти к 5-му этапу развития как предприниматель, когда человек забыл, практически не знает, как он этому научился (ему кажется, что он с рождения был таким), — неосознанная компетентность.

Учитывая то, что среди предпринимателей довольно часто встречаются не только экономисты и менеджеры, но и филологи, психологи, педагоги, социологи, математики и физики, которых также обучают в Бурятском государственном университете, необходимо на всех направлениях и профилях обучения внедрять дисциплины, связанные с подготовкой к предпринимательству. Для формирования у студентов положительного имиджа предпринимательства необходимо, чтобы именно предприниматели в первую очередь были героями у молодежи. Для этого портреты, биографии, истории успеха местных и других предпринимателей, их имена должны быть на глазах у студентов. Также необходимо периодически организовывать встречи студентов, желающих стать предпринимателями, помочь им создать что-то вроде клуба по интересам. Организовывать им встречи с известными крупными и менее известными представителями малого, среднего и даже крупного бизнеса. В качестве примера можно использовать опыт Института экономики и управления Бурятского государственного университета, где ежегодно проводятся такие встречи, налажен контакт с центром «Мой бизнес», республиканским бизнес-инкубатором, бизнес-школой «Синергия».

Для более увлекательных занятий по дисциплинам, связанным с предпринимательством, надо больше внедрять занятий в интерактивных формах. Вовлекать студентов в различные мероприятия, связанные со стартапами, создавая банк интересных предпринимательских идей и бизнес-планов. Они должны быть доступными для всех, кто желает с ними ознакомиться. Надо помнить, что большинство венчурных капиталистов заботит не славная история вуза, а то, направ- 
лен ли стартап на коммерческий успех. В учебном процессе во время проведения занятий имеет смысл больше уделять внимание практической стороне бизнеса, управления, вопросам маркетинга, финансирования, снабжения и т. п. Вместе с этим помнить, что предприниматель постоянно ищет людей, у которых можно получить ценный совет. Ими могут быть преподаватели вуза или профессионалы, которых приглашают прочитать лекцию перед студентами.

Для непрерывного роста профессионального мастерства предпринимателей необходимо периодически организовывать курсы повышения квалификации, бизнес-тренинги. Для проведения занятий с ними привлекать предпринимателей, коучей, бизнес-тренеров. Для самоподготовки предприниматели очень много полезного могут найти для себя в книгах Наполеона Хилла [3], Шарма Робина [4], В. Штерна [5], А. Парабеллума, Н. Мрочковского [6; 7] и многих других. Эти книги должны стать настольными книгами для всех студентов Бурятского государственного университета. Будущему предпринимателю следует всегда помнить слова известного предпринимателя Бодо Шеффера, что «предпринимательству можно только научиться, не научить, а именно научиться!» Поэтому в первооснове обучения студентов должна быть их самоподготовка и самообразование. И эта главная особенность в развитии предпринимательских способностей у студентов должна поддерживаться экосредой университета, всеми горизонтальными и вертикальными связями университета.

\section{Литература}

1. Потаев В. С. Организация предпринимательской деятельности (курс лекций). Улан-Удэ: Изд-во БГСХА, 2009. 160 с.

2. Хизрич Р., Питерс М. Предпринимательство, или Как завести собственное дело и добиться успеха: пер. с англ. М.: Прогресс, 1992. Вып. 1. С. 51-132.

3. Хилл Н. Думай и богатей! М.: АСТ, 2013. 384 с.

4. Шарма Робин. Монах, который продал свой «феррари»: История об исполнении желаний и постижении судьбы: пер. с англ. М.: София, 2013. 224 с.

5. Штерн В. 21 правило поведения, которое сделает вас богатым: Школа Брайана Трейси. М.: Астель, 2012. 189 с.

6. Прорыв! 11 лучших тренингов по личностному росту / А. Парабеллум [и др.]. СПб.: Питер, 2012. 352 с.

7. Парабеллум А., Мрочковский Н. Ежедневник. Как успеть все! СПб.: Питер, 2016. $480 \mathrm{c}$.

\section{ON THE FEATURES OF DEVELOPING STUDENTS' ENTREPRENEURIAL SKILLS}

Victor S. Potayev

Dr. Sci. (Econ.), Prof.,

Dorzhi Banzarov Buryat State University

24a Smolina St., Ulan-Ude 670000, Russia

E-mail: potaev_viktor@mail.ru

The article emphasizes the importance of entrepreneurship as one of the key economic factors of production, analyzes the features of people engaged in entrepreneurial activity, overviews the ways of developing entrepreneurial skills. It has been found that the character traits of entrepreneurs and managers have a lot in common. We should note, that there are also some differences in their character traits, so managers are not owners of enterprises, they are not inno- 
vators and their entrepreneurial skills are less developed. To determine the development of entrepreneurial skills of students of the Institute of Economics and Management of Buryat State University, we were tested them first in the second year of study, then in the fourth year. The results of testing showed that half of the respondents want to become entrepreneurs. But the level of entrepreneurial skills, the so-called soft skills, is unsatisfactory. In light of this we recommend to introduce special discipline for students, create the right environment for startups, and pay more attention to self-tuition of future entrepreneurs.

Keywords: entrepreneurship; entrepreneurial skills; competencies; training, self-tuition. 